\title{
A construção de uma Biblioteca na trajetória de Manuel Correia de Andrade ${ }^{\mathrm{I}}$
}

\author{
[ Book collecting in Manuel Correia de Andrade's intellectual trajectory
}

Marta Amoroso ${ }^{2}$

\section{Paulo Teixeira Iumatti ${ }^{3}$}

RESUMO Em 20I4, o Instituto de Estudos Brasileiros da USP recebeu em doação a biblioteca do intelectual Manuel Correia de Andrade (I922-2007). Trata-se de um acervo bibliográfico e arquivístico composto de mais de 45 mil itens, coletados ao longo de uma vida de intensos estudos dedicados, particularmente, ao conhecimento da região Nordeste. Neste artigo, procuramos esboçar como a construção dessa biblioteca se insere na trajetória do intelectual, identifi- cando suas temáticas e nichos principais, a partir de pesquisas bibliográficas e de visita técnica realizada em abril de 2008. Procuramos, com isso, destacar algumas das possibilidades de exploração dessa biblioteca, bem como sua contribuição interdisciplinar para os estudos brasileiros. • PALAVRasCHAVE Intelectuais brasileiros, Manuel Correia de Andrade, Nordeste, documentação bibliográfica e arquivística, Brasiliana, estudos interdisciplinares.

DOI: http://dx.doi.org/Io.II606/issn.23I6-90IX.voi6opI99-2Io

I Texto elaborado a partir de pesquisas bibliográficas e visita técnica realizada entre 22 e 24 de abril de 2008. Agradecemos à família Correia de Andrade pelos diversos depoimentos sem os quais este texto seria impossível.

2 Universidade de São Paulo (USP, São Paulo, SP, Brasil).

3 Universidade de São Paulo (USP, São Paulo, SP, Brasil). 


\section{O INTELECTUAL MANUEL CORREIA DE ANDRADE}

Um dos maiores geógrafos brasileiros do século XX, que construiu uma obra marcante no que se refere, sobretudo, aos debates sobre a reforma agrária e o desenvolvimento regional, Manuel Correia de Andrade teve uma trajetória intelectual e profissional que se plasmou em intensa e reconhecida atuação nas esferas universitária e administrativa, bem como em vasta produção bibliográfica.

Detentor de prêmios e títulos, dentre os quais Professor honoris causa das Universidades Federais de Alagoas, Sergipe e Rio Grande do Norte e da Universidade Católica de Pernambuco, e Professor Emérito da Universidade Federal de Pernambuco, o geógrafo teve vida pública ativa a partir dos anos I940 e I950. Foi membro da Agência de Planejamento e Pesquisas de Pernambuco (Condepe); Diretor do Grupo Executivo de Produção de Alimentos (GEPA) - órgão criado por Miguel Arraes no governo de Pernambuco entre I963 e I964; Presidente da Associação dos Geógrafos Brasileiros entre I96I e I963 e Vice-Presidente da mesma AGB entre I968 e I969; bolsista, em I964, na École Pratique des Hautes Études de Paris e no Ministério da Economia francês; principal organizador e coordenador do Mestrado em Geografia da Universidade Federal de Pernambuco, criado em I977; coordenador do Mestrado em Economia da mesma Universidade; um dos criadores, na década de I980, da Associação de Pós-Graduação e Pesquisa em Geografia; Diretor do Centro de Estudos de História Brasileira (CEHIBRA) da Fundação Joaquim Nabuco entre I984 e 2002; bolsista e membro de comissões do CNPq por mais de duas décadas; pesquisador visitante da Universidade de Sukuba, no Japão, em I980; professor visitante no programa de Mestrado e Doutorado em Geografia da Universidade de São Paulo, entre I986 e I987; professor visitante em diversas universidades no Brasil e no Exterior; e parecerista e membro de diversas organizações nacionais e internacionais, como o International Council for Research in Cooperative Development (Suíça).

Se os traços gerais dessa atuação, bem como da vasta obra de Manuel Correia de Andrade foram já sobejamente destacados na bibliografia, menos conhecido é o fato de sua trajetória ter se materializado, também, no impressionante acervo bibliográfico que reuniu ao longo da vida, o qual, mantendo-se íntegro, e tendo sido zelosamente atualizado, revela o universo de seus interesses e pesquisas até o ano de sua morte4. A Biblioteca Manuel Correia de Andrade é hoje, sem dúvida, uma das principais coleções bibliográficas pessoais brasileiras, tanto pela abrangência de temas como pela exaustividade. Com efeito, a construção de um Acervo de livros monumental, como contribuição ao conhecimento do Brasil e seus problemas, parece ter sido um dos objetivos perseguidos pelo intelectual até praticamente seus últimos dias. Tal Acervo, agora oferecido como doação à Universidade de São Paulo, compõe-se de cerca de 46 mil livros, além de aproximadamente 200 pastas contendo documentos bibliográficos e/ou de arquivo (tais como correspondência ativa e passiva e manuscritos).

4 Nesse sentido, vale enfatizar também que parte da Biblioteca é constituída por exemplares com marginália - que se pode constatar, por exemplo, em obras de Capistrano de Abreu, Orlando Valverde, Celso Furtado, Josué de Castro e Milton Santos. 
O Acervo como um todo mostra um Brasil pensado a partir do prisma de suas características regionais, bem como de seus dilemas como nação e de sua inserção internacional no século XX e em inícios do século atual. Sobressaem-se nele tanto a busca da compreensão das diversidades regionais e sub-regionais e das desigualdades sociais, como o prisma de sua articulação em diversas escalas 5 , a partir de uma ótica interdisciplinar. Tal ótica é construída pelo entroncamento de conhecimentos das áreas de História, Geografia, Sociologia, Direito e Economia, em que as relações entre natureza e sociedade se cruzam, constantemente. Voltado sobretudo ao estudo do Nordeste e ao combate à pobreza, à concentração da riqueza e à exploração social, Manuel Correia de Andrade procurou, ao longo de sua trajetória, tecer essas relações, assim como as mediações entre o particular e o geral, o regional e o nacional, o local e o global, a partir do prisma da dialética ${ }^{6}$.

Articulando-se a esse viés, dentre as publicações de sua lavra, em meio às quais contam-se ensaios, obras didáticas, paradidáticas, teses etc., figuram cerca de cem livros, com grande diversidade temática7. A título de exemplo, podemos vislumbrar, nesse conjunto, temas relativos a aspectos específicos da realidade geográfica, social e histórica nordestina, nortista ou pernambucana, como a geografia regional do vale do Siriji (I958); a pecuária no agreste pernambucano (I96I); a guerra dos cabanos (I965); os movimentos nativistas em Pernambuco (I97I); a dinâmica das microrregiões de intensa atividade migratória do Nordeste (I980); a organização do espaço rural e urbano da área de irrigação do submédio São Francisco (I983); a história da usina de açúcar de Pernambuco (I989); a cassiterita nas Regiões Norte e Nordeste do Brasil (I99I); o sal marinho e a produção do espaço geográfico no Rio Grande do Norte (I995); e as usinas e destilarias de Alagoas (I997), dentre muitos outros. De outro lado, encontram-se também temas gerais ou teóricos, como os relativos ao desenvolvimento regional (1967); à reforma agrária e às lutas camponesas no Nordeste e no Brasil (I963; I970; I983); à industrialização nordestina (I98I); à Ecologia (I994); às questões mais amplas relativas à Economia, ao Planejamento, ao Território, à identidade nacional, à globalização e ao próprio estatuto teórico e epistemológico da Geografia (I995; I996; 2002), dentre outras.

Trata-se, portanto, de obra vasta, cuja amplitude pode ser também entrevista na fortuna crítica que vem se acumulando nos últimos anos ${ }^{8}$. Ora, uma listagem

5 No prefácio à sexta edição de A Terra e o Homem no Nordeste, escreveu, por exemplo, que sua obra "não é apenas um estudo regional, é também um estudo nacional, de vez que projeta a região no país como um todo e conduz a discussão em função dos sistemas e da realidade nacionais”. ANDRADE, Manuel Correia de. A Terra e o Homem no Nordeste - Contribuição ao Estudo da Questão Agrária no Nordeste. 6. ed. Recife, UFPE, I998, p. I3.

6 ARAÚJO, Rita de Cássia Barbosa de (org.). O Fio e a Trama: Depoimento de Manuel Correia de Andrade. Recife, UFPE, 2002, p. I48-I49.

7 Ver GASPAR, L. (coord.); PORDEUS, R.; SILVA, R. Manoel Correia de Andrade: Cronologia e Bibliografia. Recife, UFPE, I996; VAINSENCHER, Semira Adler. Manoel Correia de Andrade. Portal da Fundação Joaquim Nabuco. Disponível em:<goo.gl/62Gk6N> Acesso em: 28 abr. 2008.

8 Podemos destacar nesse sentido os vários depoimentos e estudos publicados no livro Manuel Correia de Andrade - um Homem Chamado Nordeste, organizado por L. Rivas, C. Cavalcanti e J. Ribemboim (Recife, 
inicial dos livros que pertenceram a Manuel Correia de Andrade, bem como de sua distribuição temática, indica que sua Biblioteca foi um dos principais alicerces dessa profícua produção intelectual.

Em meio a essa produção, contam-se trabalhos de peso no cenário acadêmico e político brasileiro a partir dos anos I950, dentre os quais se destaca, sobretudo, A Terra e o Homem no Nordeste - Contribuição ao Estudo da Questão Agrária no Nordeste, de I963. O livro foi eleito, em 2000, pela Câmara Brasileira do Livro, um dos cem livros brasileiros mais importantes do século XX. Considerado um estudo inovador, que inaugurou um novo caminho para a compreensão do espaço regional, em virtude da relação que constrói entre espaço e relações sociais, afim com a de pensadores como Caio Prado Jr., Josué de Castro e Celso Furtado, foi acolhido não apenas por geógrafos, mas também por sociólogos, economistas, historiadores e pelos próprios movimentos sociais, que o reputaram como marco nos estudos sobre a reforma agrária no Brasil. Note-se que, nele, a região - ou antes, o "mosaico regional" do Nordeste - aparecerá não como parte de um discurso homogeinizador, mas como algo a ser escrutinado numa posição intermediária entre a particularidade e a generalidade, mantendo-se a tensão entre a síntese como instrumento do pensamento crítico e os traços individuais nunca ignorados. Nesse sentido, as monografias que Manuel Correia de Andrade redigiu como autor ou coautor, como A Pecuária no Agreste Pernambucano 9 e Os Rios-do-açúcar do Nordeste Oriental ${ }^{\text {To }}$, foram certamente decisivas em sua trajetória intelectual, podendo ser lidas como parte do percurso que resultou no grau de elaboração alcançado naquele livro. Em A Terra e o Homem no Nordeste, destaca-se, assim, como procedimento metodológico, a análise das diversificações dentro de uma mesma área ${ }^{\mathrm{II}}$, as quais diziam respeito tanto a condições

Edições Bagaço, 2008), bem como nos números especiais dedicados a Manuel Correia de Andrade das revistas Scripta Nova: Revista Electrónica de Geografía y Ciencias Sociales, Universidad de Barcelona, v. XIII, n. 288, abr. 2009 (Cidadania e Reforma Agrária no Brasil: a Herança de Manuel Correia de Andrade. Número especial coordenado por Wagner Costa Ribeiro e Paulo Roberto Rodrigues Soares. Disponível em: <goo. gl/KtdjpZ>. Acesso em: 3 set. 20I4) e Economia Política do Desenvolvimento, Maceió, v. 3, Edição especial dedicada a Manuel Correia de Andrade, ago. 20Io. Disponível em: 〈goo.gl/2euooU〉. Acesso em: I4 ago. 2014. Ver também, dentre muitos outros, os artigos de MARQUES DE MELO, José. Espaço, Tempo e Movimento: Contribuições de Manuel Correia de Andrade para a Geografia da Comunicação. Alceu, v. Io, n. Io, p. 82-99, jan./jun. 20Io. Disponível em: <goo.gl/Qrzo2K> Acesso em: 8 set. 2014; Saquet, Marcos Aurelio. Contribuições para o Entendimento da Obra de Manuel Correia de Andrade: Geografia, Região, Espaço e Território. Geo UERJ, ano I2, n. 2I, v. 2, 2 ' sem. 20Io. Disponível em: 〈goo.gl/UDSXUo〉. Acesso em: 8 set. 20I4; Ávila Martins, César Augusto. Geografia, Economia e Planejamento na Obra de Manuel Correia de Andrade. Geosul, Florianópolis, v. 26, n. 5I, p. 9-37, jan./jun. 20II. Disponível em: 〈goo.gl/G4GBtM〉Acesso em: I8 ago. 20I4; e CARVALHO, Cícero Péricles de Oliveira. Manuel Correia de Andrade e a Economia Política do Nordeste. Revista Econômica do Nordeste, Fortaleza, v. 54, n. 2, p. 6-I6, abril/jun. 20I4. Disponível em: <http://goo.gl/ cRKq8v>. Acesso em: 8 set. 20I4.

9 ANDRADE, Manuel Correia de. A Pecuária no Agreste Pernambucano. Tese apresentada para provimento da Cátedra de Geografia Econômica, Recife, Universidade do Recife, I96I.

Io ANDRADE, Gilberto Osório de Oliveira; Andrade, Manuel Correia de. Os Rios-do-açúcar do Nordeste Oriental. Recife, Instituto Joaquim Nabuco de Pesquisas Sociais, I957-I959. 2 v.

II “[...] Aí é que a participação do geógrafo no planejamento é indispensável, uma vez que ninguém melhor 
naturais como a formas de atividade humana ${ }^{\mathrm{I}}{ }^{2}$. Diversificações concretas, de desenhos complexos, que apenas um conhecimento empírico profundo, em interação com a reflexão teórica e a busca da síntese, poderia captar ${ }^{\text {T3 }}$.

Ora, quando olhamos para a Biblioteca reunida por Manuel Correia de Andrade, podemos constatar, em primeiro lugar, uma convergência entre esse pensamento e o seu conteúdo, estrutura e organização. Com efeito, ela se constituiu, em uma de suas principais vertentes - e embora não se esgotando nela-, de forma a reunir sistematicamente todas as informações e conhecimentos produzidos sobre a região Nordeste em sua extrema diversidade, dentro e fora da mesma, num amplo recorte temporal. Nesse particular, tal Acervo, conservado em sua integridade, talvez não encontre paralelos no Brasil.

Além disso, espelha não apenas esse universo de interesses e pesquisas a partir de uma perspectiva social crítica, atenta tanto às singularidades como à síntese, mas também uma trajetória profissional e de engajamento institucional muito peculiar, a qual interagiu, como vimos na breve listagem com que iniciamos este texto, com uma multiplicidade de órgãos voltados à construção de conhecimento e coleta e sistematização de dados sobre a "realidade brasileira" e o "Nordeste", em múltiplos níveis e diversos momentos. Assim, o Acervo traz as marcas das posições estratégicas que seu Titular foi assumindo ao longo de sua trajetória no campo intelectual, político e administrativo nordestino e brasileiro, como as de Presidente e Vice-Presidente da AGB, coordenador de programas de pós-graduação e Diretor do CEHIBRA da Fundação Joaquim Nabuco.

Por fim, acrescente-se que Manuel Correia de Andrade foi, desde a adolescência, como ele próprio reconhecia, um leitor e colecionador de livros compulsivo. Em sua visita ao IEB, em 2003, e em um de seus livros de depoimentos, o geógrafo observou que sua Biblioteca crescia nos últimos anos a uma proporção de cerca de cem livros por mês ${ }^{14}$, ocupando dois apartamentos que possuía no Recife, na rua da Amizade, além de um gabinete em sua residência na Rua do Espinheiro. Note-se, a propósito, que tal Coleção possui mais do que o dobro do montante de livros de cada uma das maiores Bibliotecas pessoais do IEB-USP - complementando, em particular, as coleções tematicamente afins de intelectuais como Mário de Andrade, Graciliano Ramos, Caio Prado Jr., Pierre Monbeig e Milton Santos - sem contar o rico acervo de folhetos de cordel da instituição.

do que ele pode indicar as regiões e sub-regiões em que se divide uma área." ANDRADE, Manuel Correia de. A Terra e o Homem no Nordeste. 2. ed. São Paulo, Brasiliense, I964, p. 239.

I2 Assim, as grandes regiões trabalhadas no livro - a Zona da Mata, o Agreste e o Sertão - possuíam inúmeras diferenciações internas, que era vital considerar, como fica claro no início de uma das seções do capítulo “Propriedade, Policultura e Mão-de-Obra no Agreste”: “O Agreste, região de transição que é, possui variações mesológicas bem mais acentuadas que a Mata e o Sertão. Apresenta grandes diversificações no tipo de uso da terra e, conseqüentemente, nas relações de trabalho no campo. Por isto, neste capítulo em que pretendemos retratar as condições de vida e o trabalho do homem que moureja a terra, procuraremos focalizar o verdadeiro mosaico que é a região." ANDRADE, M. C. de, op. cit., I964, p. I54.

I3 Ver IUMATTI, P. T. Saberes populares no Nordeste. In: RIVAS, L; CAVALCANTI, C.; RIBEMBOIM, J. (orgs.).

Manuel Correia de Andrade - um Homem Chamado Nordeste. Recife, Edições Bagaço, 2008, p. I33-I4I.

I4 "[...] Entra uma média de cem livros por mês, na minha biblioteca, porque recebo muito livro, compro muito livro. Eu não posso ler nem um terço." ARAÚJO, Rita de Cássia Barbosa de (org.), op. cit., p. I59-I60. 


\section{A CONSTRUÇÃo da BIBLIOTECA NA RUA DA AMIZADE}

A Biblioteca e o Arquivo de Manuel Correia de Andrade datam de momentos distintos da trajetória do intelectual, sendo que a primeira antecede no tempo as práticas de sistematização do Arquivo pessoal. Com efeito, a Biblioteca começou a ser reunida nos anos I930 - no momento em que o adolescente passou a residir no Recife e a cursar a escola regular, utilizando o dinheiro das semanadas que recebia do pai para a aquisição de livros em sebos do centro da cidade. Assim, ainda naqueles anos, o jovem começou a reunir as coleções de estudos brasileiros publicadas na época, como a Coleção Brasiliana, a Biblioteca Brasileira, a Documentos Brasileiros, a Problemas Brasileiros e outras coleções de editoras pequenas, que ele se empenharia em completar. Como ele mesmo observou:

Bem, sou maníaco por livro. É uma coisa compulsiva. Comecei a juntar livros com I4 anos de idade, sobre assuntos brasileiros. Juntei a Coleção Brasiliana, a Coleção Documentos Brasileiros, a Biblioteca Documentos Brasileiros. Tenho as coleções todas. E outras pequenas coleções, que surgiram em pequenas editoras e viveram pouco tempo. Fui juntando livros em casa [...].15

Aos primeiros títulos de seu Acervo da juventude logo se somaram os volumes da Biblioteca particular da família, herança deixada a Manuel Correia de Andrade por seu pai, Joaquim Correia Xavier de Andrade, proprietário do Engenho Judiá, em Vicência, na Mata Norte de Pernambuco (local de nascimento do geógrafo). Dentre tais volumes, contavam-se obras jurídicas e também geográficas, como a coleção completa de livros de Elisée Reclus: a Nouvelle Geographie Universelle (I7 volumes) e L'Homme et la Terre (I905, 6 volumes). Não por acaso, Manuel Correia seria, nos anos I980, o organizador do volume sobre Reclus da coleção “Grandes Cientistas Sociais”, da editora Ática ${ }^{\mathrm{I6}}$ :

Encontrei o livro do Reclus, pela primeira vez, na estante do meu pai, e achei a leitura muito interessante. Depois da década de I930, o Reclus ficou um pouco esquecido, devido à forte influência, aqui no Brasil, exercida por estudiosos franceses, que refutavam o seu trabalho. ${ }^{\text {I7 }}$

Além dessas raízes afetivas e familiares, os temas da Biblioteca de Manuel Correia de Andrade nos ajudam a acompanhar o percurso do pesquisador, cujos interesses estiveram localizados nas Humanidades em posição estratégica, de interseção com a Geografia Física. No período de formação universitária e início das atividades profissionais, eles voltaram-se marcadamente para as áreas do Direito, da Política, da

I5 ARAÚJO, Rita de Cássia Barbosa de (org.), op. cit. p. I57.

I6 ANDRADE, Manuel Correia de. Elisée Reclus. São Paulo, Ática, I985 (Coleção Grandes Cientistas Sociais). I7 ANDRADE, Manuel Correia de. Faces de uma Amizade: Manuel Correia de Andrade e Caio Prado Jr. Entrevista com Manuel Correia de Andrade. In: HEIDEMAN, Heiz Dieter; IUMATTI, Paulo; SEABRA, Manoel (orgs.). Caio Prado Jr. e a Associação dos Geógrafos Brasileiros. São Paulo, Edusp/IEB/AGB/Fapesp, 2008. p. I97. 
Geografia, da Economia e da História. Entre I945 e I947, Manuel Correia de Andrade obteve os diplomas de Direito, na tradicional Faculdade de Direito do Recife, e de Licenciatura em Geografia e História, concluída na Faculdade de Filosofia, Ciências e Letras "Manoel da Nóbrega" (hoje Universidade Católica de Pernambuco). Estabeleceu então seu escritório de advocacia na rua do Imperador, no Recife. Data dessa época a aquisição de títulos clássicos do Direito, de História e Geografia Geral e do Brasil, além de uma coleção significativa de literatura regional, temas gerais que ele manteve atualizados ao longo da vida, com destaque para a biblioteca de História e de Geografia regional e do Brasil.

Formado, o bacharel passou a atuar como advogado trabalhista independente junto a trabalhadores rurais dos sindicatos dos Ferroviários, dos Trabalhadores da Indústria de Exploração de Pedras de Jaboatão e dos Trabalhadores da Indústria de Papel e de Papelão. Dessa atuação profissional, que se inicia em I947, o Acervo Manuel Correia de Andrade guarda volume bibliográfico e documental significativo que trata da situação dos trabalhadores rurais e urbanos nas regiões Norte e Nordeste, bem como de organizações trabalhistas e políticas em geral. É também nos anos I940 que se inicia sua coleção de clássicos da teoria política e do marxismo - lembre-se que, em I942, Manuel Correia de Andrade filiou-se, conquanto por apenas alguns meses, ao Partido Comunista.

A despeito de permanecer por toda vida ligado à Ordem dos Advogados do Brasil, Manuel Correia de Andrade gradativamente deixou de adquirir títulos da área do Direito, na medida em que suas opções profissionais migraram para o ensino e a pesquisa da Geografia. Ocorreu assim, no repertório de títulos ligados ao Direito, uma descontinuidade de algumas décadas. O tema, entretanto, voltou à mira do pesquisador nos anos I990 e 2000, especialmente depois que assumiu a "Cátedra Gilberto Freyre" da Universidade Federal de Pernambuco, quando retomou seu antigo interesse pelo Direito Internacional, agora na sua interface com as questões do ambientalismo e da globalização, bem como as questões políticas ligadas às relações entre ambiente e sociedade, temáticas estas tratadas nos cursos que ministrou a partir de 2000. Fez parte desse novo universo de interesses um número significativo de títulos adquiridos nas últimas duas décadas, com destaque para as publicações recentes sobre a Amazônia e suas particularidades socioambientais.

Destarte, o interesse pela região Norte, que o intelectual já acusa na década de I950 - quando passa a adquirir títulos relacionados à pesca, à pecuária e especialmente aos ciclos extrativistas na Amazônia - completa-se com o debate sobre o desenvolvimento sustentável da região, que se inicia na Biblioteca em meados dos anos I980 e se mantém atualizado até o final da vida.

Voltemos, porém, a um momento anterior. Foi no final da década de I940 que o pesquisador amadureceu a intenção de abandonar gradativamente o Direito como área de atuação profissional e especializar-se no ensino e pesquisa da Geografia. A leitura da obra de Caio Prado Jr. ${ }^{18}$ - intelectual que conheceu em I945, em viagem realizada a São Paulo - parece ter sido decisiva nessa guinada profissional, que o levou a deixar a advocacia e a passar a participar da rede de intelectuais articulada

I8 Idem. 
a instituições como o Ginásio Pernambucano, a recém fundada Universidade Federal de Pernambuco e o Instituto de Pesquisas Joaquim Nabuco. O jovem estudioso iniciou aí uma intensa colaboração com os principais expoentes da Geografia pernambucana de então, os geógrafos Gilberto Osório de Andrade e Mário Lacerda. A partir de I952, passou a lecionar Geografia no ensino médio, nos colégios Vera Cruz, Padre Felix e Americano Batista, no Recife.

Nesse mesmo período, Manuel Correia de Andrade e sua Biblioteca voltaram-se, também, para a temática dos movimentos sociais e políticos na região Nordeste. $\mathrm{O}$ pesquisador realizou então investigações sistemáticas na Biblioteca e Arquivo Público de Pernambuco, que resultaram em artigo sobre as sedições de I83I em Pernambuco (I956), em livro sobre a história dos conflitos sociais no período da Regência (A Guerra dos Cabanos, um dos estudos pioneiros sobre a revolta, publicado em $1965^{\text {I9 }}$ ), e, em diversos momentos, em trabalhos que se debruçaram sobre movimentos como a Revolução Praieira e o da formação de quilombos.

Nos anos I950, Manuel Correia de Andrade tornou-se Doutor em Economia na Universidade Federal de Pernambuco, tendo concluído, em I956, o Curso de Altos Estudos Geográficos na Faculdade Nacional de Filosofia da Universidade do Brasil. A década de I960 é marcada pela participação do intelectual, que já alcançara grande prestígio como estudioso da vida econômica, geográfica e social do Nordeste, e sobretudo da questão agrária, no governo de Miguel Arraes em Pernambuco, quando passou a dirigir o Grupo Executivo de Produção de Alimentos - órgão que se ligava às agências do Banco do Brasil para levar empréstimos aos pequenos produtores rurais. Tornou-se também membro do Conselho Estadual de Educação, em I964. Depois de sua prisão nesse mesmo ano, e de um período de exílio na Europa, Manuel Correia de Andrade retornou ao país, tendo presidido o Grupo de Trabalho para a elaboração de Sugestões para a Reforma Agrária, no final dos anos $1960^{20}$. Note-se que nessa fase parece ter se encetado a reunião daquilo que seria uma importante parte de seu Acervo, já que inexistente ou rara em bibliotecas do Centro-Sul, composta das coleções integrais de boletins institucionais dos diferentes órgãos de fomento e desenvolvimento regional da segunda metade do século XX.

A prisão de Manuel Correia de Andrade em I964 deveu-se tanto por sua participação no Governo Arraes como "também por ser reconhecida sua militância, na década de I950 e começo dos anos I960, no Partido Socialista Brasileiro e pela passagem breve no Partido Comunista Brasileiro”2 de 1960 e do período posterior à ditadura militar foram por ele acompanhados por pesquisa sistemática em jornais, como pudemos observar em seu Arquivo. Por outro lado, entre I964 e I965, quando obteve sua especialização no Curso de Estudos Avançados do Instituto da América Latina da Universidade de Paris, Manuel Correia de Andrade voltou seus interesses para as temáticas do desenvolvimento e da pobreza na África e na América do Sul; da teoria dos polos; do socialismo e dos programas

I9 ANDRADE, Manuel Correia de. A Guerra dos Cabanos. Rio de Janeiro, Conquista, I965.

20 Ver MAIA, Doralice Sátyro, O Pensamento de Manoel Correia de Andrade e a Sua Obra A Terra e o Homem no Nordeste. Scripta Nova, v. XIII, n. 288, I5 abr. 2009. Disponível em: 〈goo.gl/ou6CJC〉. Acesso em: I2 set. 20I4. 2I CARVALHO, Cícero Péricles de Oliveira, op. cit., p. 9. 
agrícolas no regime socialista chinês. Observa-se, também, paralelamente, o cultivo de estudos na área de Desenvolvimento Urbano. A propósito, obras desse ramo do conhecimento ocupavam uma das duas salas repletas de livros que o geógrafo possuía na Universidade Federal de Pernambuco, os quais, depois de sua aposentadoria, juntaram-se aos demais volumes de seu apartamento na Rua da Amizade ${ }^{22}$.

Desde as primeiras publicações, na juventude, até o momento em que, nos anos I980, a convite de Gilberto Freyre, passou a integrar, como Diretor do CEHIBRA, o grupo de pesquisadores da Fundação Joaquim Nabuco, onde permaneceu por I6 anos, Manuel Correia de Andrade dedicou-se ao trabalho de campo, acompanhando, nos últimos anos, as muitas mudanças no Nordeste advindas das atividades industriais, turísticas e outras ${ }^{23}$. Como já ocorria nos anos I950, a investigação de campo era preparada por um levantamento bibliográfico sistemático que resultava no crescimento do Acervo. Também mais recentemente, quando passou a atuar na Cátedra Gilberto Freyre da UFPE, após sua saída da direção do CEHIBRA, as viagens de campo, que envolviam a ampliação do Acervo, se mantiveram.

A entrada na direção do CEHIBRA nos anos I980 marcou o incremento da produção de Manuel Correia de Andrade na área de História, tendo seu movimento de aquisição de livros e outras publicações acompanhado tal direção. O intelectual produziu regularmente, nessa fase que se estende até depois de sua saída da FUNDAJ, sobre temas como a revolução de I930 (I980; I988), a abolição e a reforma agrária (I987), a história das usinas de açúcar de Pernambuco (I989) e a vida e a obra de Pereira da Costa (2002). Assim, a partir dos anos I980, acompanhando sua posição privilegiada como Diretor daquele centro, sua Biblioteca manteve-se atualizada em relação à produção historiográfica nordestina em sua multiplicidade, em suas facetas universitária - muitas vezes de difícil acesso no Centro-Sul - e extra-universitária, como é o caso de obras históricas, memórias e crônicas surgidas no âmbito de centros de estudos e de memória ligados aos poderes municipais, estaduais ou independentes. Assim, por exemplo, dentre muitas outras, verifica-se a presença de publicações da Universidade Federal do Ceará, como os volumes de sua "Coleção Estudos Históricos", e do Centro de Estudos de História Municipal de Pernambuco, como a "Coleção Biblioteca Pernambucana de História Municipal” (completa até o volume 27).

Lembre-se também que a atuação no Joaquim Nabuco e, depois, à frente da Cátedra Gilberto Freyre da UFPE, levaram o intelectual a se debruçar cada vez mais sobre a questão da atualidade da obra dos chamados intérpretes do Brasil. Desse

22 "Mas eu tinha duas salas na universidade, todas cheias de livros: uma, em Geografia, e outra, em Desenvolvimento Urbano. Quando me aposentei, aconteceu que tive de deixar as salas. Mas meus filhos estavam casando. Estavam deixando os quartos desocupados e fui enchendo-os de livros. [...]” ARAÚJO, Rita de Cássia Barbosa de (org.), op. cit., p. I57.

23 Ver, por exemplo, um dos últimos textos produzidos pelo geógrafo, cedido por sua Família, para publicação na Revista do Instituto de Estudos Brasileiros da USP. ANDRADE, Manuel Correia de. Pernambuco e o Trópico. Revista do Instituto de Estudos Brasileiros, São Paulo, n. 45, set. 2007, p. II-20. Disponível em: <http://goo.gl/B4sull >. Acesso em: I jan. 2015. 
movimento resultou a realização de seminários e livros, como Gilberto Freyre e os Grandes Desafios do Século XX ${ }^{24}$.

Transcendendo, porém, alguns interesses mais momentâneos ou aqueles interesses "persistentes", já que inseparáveis do viés totalizador e interdisciplinar marcado pelo diálogo com o marxismo, como aqueles relativos à História ou mesmo ao debate em torno das interpretações do Brasil, pode-se dizer que o foco central das leituras de Manuel Correia de Andrade ao longo de toda a sua vida girou em torno da questão agrária, da Geografia Física e Humana e das relações de poder no Nordeste. Com efeito, é o Nordeste em toda a sua diversidade e transformações ao longo do tempo, suas várias sub-regiões e incontáveis localidades, que abrange a parte mais expressiva do Acervo, tendo o interesse remarcado pela Geografia Física e Humana nordestina, norteado pela questão do desenvolvimento, permanecido atualizado na Biblioteca até o começo dos anos 2000. Boa parte da Biblioteca diz respeito a essa vasta vertente, para a qual o intelectual dá contribuição de inestimável valor, reunindo publicações de tiragem restrita e/ou de dificílimo acesso.

O Acervo Manuel Correia de Andrade expressa, desta forma, um interessante movimento de atualização temática constantemente refeita, ao mesmo tempo que inscreve em sua materialidade uma clara linha de continuidade de interesses que acompanham o intelectual em sua trajetória e que particularizam sua contribuição no cenário da crítica moderna desenvolvida pelas Ciências Sociais, projetando, para além dela, a atualidade do próprio Acervo nos debates acadêmicos contemporâneos. Referimo-nos, por exemplo, a linhas de interesse originalmente ligadas à questão do Direito Trabalhista, no final dos anos I940, e que caminham, ao longo dos decênios de I950 e I960, rumo ao debate em torno das políticas públicas voltadas ao desenvolvimento econômico e a questão da reforma agrária, para acompanhar ao longo dos anos I990 e na virada do século XXI, por meio de cursos e publicações, as questões políticas que abrangem a temática do Direito Ambiental no mundo globalizado: a exploração dos nichos ecológicos pelos programas de povoamento e desenvolvimento regionais e as consequências ambientais que dela decorrem.

Sem que o Acervo desmereça processos que se dão nas demais regiões do país, para as quais o intelectual e autor de livros didáticos dedicou grande atenção ${ }^{25} \mathrm{e}$ sobre as quais colecionou um número significativo de volumes, os temas ligados à reforma agrária, ao desenvolvimento e às relações entre sociedade e natureza, privilegiando as regiões Nordeste e Norte, seus sistemas econômicos e ecológicos, abrem grandes possibilidades de estudo interdisciplinar, marcadamente no que tange à articulação entre a Geografia, a História, a Antropologia, o Direito, a Economia e a Sociologia. De fato, possibilitando essa exploração das relações entre sociedade e natureza, o Acervo Manuel Correia de Andrade transforma-se em rico manancial

\footnotetext{
24 ANDRADE, Manuel Correia de. Gilberto Freyre e os Grandes Desafios do Século XX. São Paulo, Vozes, 2002. 25 Defendendo, por exemplo, a atuação do Estado como anteparo a processos econômicos e sociais violentamente concentradores, que geram "fortunas colossais e miséria excessiva [...]" ANDRADE, M. C. de. Modernização e Pobreza - a Expansão da Agroindústria Canavieira e Seu Impacto Ecológico e Social. São Paulo, Unesp, I994, p. 2I9.
} 
para as diversas vertentes dos estudos brasileiros, as quais têm a potencialidade de contribuir de forma decisiva para uma infinidade questões - sociais, políticas, acadêmicas - que ultrapassam seus próprios recortes.

\section{SOBRE OS AUTORES}

MARTA AMOROSO Professora do Departamento de Antropologia da FFLCH da Universidade de São Paulo. Vice-diretora do IEB-USP entre 2006 e 2010.

E-mail: mramoroso@usp.br

PaUlo TeIXeIra IUMatTi Professor do Instituto de Estudos Brasileiros da Universidade de São Paulo (área de História). Vice-diretor do IEB-USP entre 2015 e 2019. E-mail: ptiumatt@usp.br

\section{REFERÊNCIAS BIBLIOGRÁFICAS}

ANDRADE, Manuel Correia de. A Pecuária no Agreste Pernambucano. Tese apresentada para provimento da Cátedra de Geografia Econômica, Recife, Universidade do Recife, I96I. . A Terra e o Homem no Nordeste - Contribuição ao Estudo da Questão Agrária no Nordeste. 6. ed. Recife, UFPE, I998. . A Terra e o Homem no Nordeste. 2. ed. São Paulo, Brasiliense, I964. . Elisée Reclus. São Paulo, Ática, I985 (Coleção Grandes Cientistas Sociais) . Faces de uma Amizade: Manuel Correia de Andrade e Caio Prado Jr. Entrevista com Manuel Correia de Andrade. In: HEIDEMAN, Heiz Dieter; IUMATTI, Paulo; SEABRA, Manoel (orgs.). Caio Prado Jr. e a Associação dos Geógrafos Brasileiros. São Paulo, Edusp/IEB/AGB/Fapesp, 2008. . Gilberto Freyre e os Grandes Desafios do Século XX. São Paulo, Vozes, 2002. - Globalização e identidade nacional. Recife: Bagaço, 2002 . Modernização e Pobreza - a Expansão da Agroindústria Canavieira e Seu Impacto Ecológico e Social. São Paulo, Unesp, I994.

. Pernambuco e o Trópico. Revista do Instituto de Estudos Brasileiros, São Paulo, n. 45, set. 2007, p. II-20. Disponível em: 〈http://googl/Błsull〉. Acesso em: I jan. 2015.

.; ANDRADE, Gilberto Osório de Oliveira. Os Rios-do-açúcar do Nordeste Oriental. Recife, Instituto Joaquim Nabuco de Pesquisas Sociais, I957-I959. 2 v.

ARAÚJO, Rita de Cássia Barbosa de (org.). O Fio e a Trama: Depoimento de Manuel Correia de Andrade. Recife, UFPE, 2002.

ÁVILA MARTINS, César Augusto. Geografia, Economia e Planejamento na Obra de Manuel Correia de Andrade. Geosul, Florianópolis, v. 26, n. 5I, p. 9-37, jan./jun. 20II. Disponível em: <goo.gl/ G4GBtM >. Acesso em: I8 ago. 20I4.

CARVALHO, Cícero Péricles de Oliveira. Manuel Correia de Andrade e a Economia Política do Nor- 
deste. Revista Econômica do Nordeste, Fortaleza, v. 54, n. 2, p. 6-I6, abril/jun. 20I4. Disponível em: 〈http://goo.gl/cRKq8v >. Acesso em: 8 set. 20I4.

ECONOMIA Política do Desenvolvimento, Maceió, v. 3, Edição especial dedicada a Manuel Correia de Andrade, ago. 20Io. Disponível em: 〈goo.gl/2euooU〉. Acesso em: I4 ago. 2014.

ENTREVISTA com a Profa. Thais de Lourdes Correia de Andrade, Recife, 23 abr. 2008, Arquivo IEB-USP.

EVANGELISTA, Helio de Araujo. A Geografia na Universidade Brasileira. Geo-paisagem, ano 3, n. 6, jul./dez. 2004.

GASPAR, L. (coord.); PORDEUS, R.; SILVA, R. Manoel Correia de Andrade: Cronologia e Bibliografia. Recife, UFPE, I996.

IUMATTI, P. T. Saberes populares no Nordeste. In: RIVAS, L; CAVALCANTI, C.; RIBEMBOIM, J. (orgs.). Manuel Correia de Andrade - um Homem Chamado Nordeste. Recife, Edições Bagaço, 2008.

LIMA, Marcos Costa. Homenagem a Manoel Correia de Andrade. A Geografia e a Política do Nordeste Brasileiro. RBCS, v. 22, n. 65, out. 2007.

MAIA, Doralice Sátyro, O Pensamento de Manoel Correia de Andrade e a Sua Obra A Terra e o Homem no Nordeste. Scripta Nova, v. XIII, n. 288, I5 abr. 2009. Disponível em: 〈goo.gl/ou6CJC〉. Acesso em: I2 set. 20I4.

MARQUES DE MELO, José. Espaço, Tempo e Movimento: Contribuições de Manuel Correia de Andrade para a Geografia da Comunicação. Alceu, v. Io, n. Io, p. 82-99, jan./jun. 20Io. Disponível em: 〈goo.gl/Qrzo2K〉. Acesso em: 8 set. 2014

RIBEIRO, W. C. et al. Scripta Nova: revista electrónica de Geografía y Ciencias Sociales, Universidad de Barcelona, v. XIII, n. 288, abr. 2009. Cidadania e Reforma Agrária no Brasil: a herança de Manuel Correia de Andrade. Número especial coordenado por Wagner Costa Ribeiro e Paulo Roberto Rodrigues Soares. Disponível em: 〈goo.gl/KtdjpZ〉. Acesso em: 3 set. 2014 .

RIVAS, L; CAVALCANTI, C.; RIBEMBOIM, J. (orgs.). Manuel Correia de Andrade - um Homem Chamado Nordeste. Recife, Edições Bagaço, 2008.

SAQUET, Marcos Aurelio. Contribuições para o Entendimento da Obra de Manuel Correia de Andrade: Geografia, Região, Espaço e Território. Geo UERJ, ano I2, n. 2I, v. 2, $2^{\circ}$ sem. 20Io. Disponível em: 〈goo.gl/UDSXUo〉 Acesso em: 8 set. 20I4.

VAINSENCHER, Semira Adler. Manoel Correia de Andrade. Portal da Fundação Joaquim Nabuco. Disponível em: <goo.gl/62Gk6N> Acesso em: 28 abr. 2008. 